\title{
Investigation on hepatitis B surface antigen among exit personnel at Tianjin port of China in 2019
}

\author{
Shao Cuicui ${ }^{\# \#}$, Chen Xiaojun ${ }^{2 \#}$, Wang Chunqi ${ }^{2}$ and Niu Guoyu ${ }^{1 *}$ \\ ${ }^{1}$ School of Public Health, WeiFang Medical University, China \\ ${ }^{2}$ Laizhou Center for Disease Control and Prevention, China \\ "Equal contribution
}

\begin{abstract}
Objective: To investigate the hepatitis B infection situation of exit physical examination personnel at Tianjin port in 2019, so as to provide data support and theoretical guarantee for disease prevention and dynamic monitoring of hepatitis B infection among physical examination population at Tianjin port.

Methods: The venous blood samples of exit personnel at Tianjin port in 2019 were collected, and the hepatitis B antigen in the samples were detected by Electrochemiluminescence technology. According to the collected passenger information, combined with the experimental results, a database of entry-exit medical examination personnel was established and the epidemiological characteristics of hepatitis B were analyzed by statistical method.

Results: A total of 3469 people were involved in this study, 134 of them were HBsAg positive, the positive rate was $3.90 \%$. From the perspective of gender, the positive rate of male was $5.51 \%(127 / 2303)$ and that of female was $0.60 \%$ (7/1166). The difference of HBV infection level between male and female was statistically significant $\left(x^{2}=50.62, \mathrm{P}<0.001\right)$. According to the analysis of different occupations, the positive rate of public servants was the highest, up to $69.10 \%(85 / 123)$; the rest were labor service personnel, pilgrims, crew members and overseas students. The difference of hepatitis B infection level among different occupational groups was statistically significant $\left(\mathrm{x}^{2}=1451.82, \mathrm{P}<0.001\right)$. The data were divided into 4 groups according to their ages. No positive results were found in $0-20$ years old people. The positive rate of 21-40 years old group was 3.23\% (84/2597). The positive rate of 41-60 years old group was 10.62\% (50/471); the positive rate of people older than 60 years old was not detected, and the difference of hepatitis B infection level among different age groups was statistically significant $\left(x^{2}<76.16, \mathrm{P}<0.001\right)$.

Conclusions: There are significant differences between the positive detection rate of hepatitis B surface antigen and the gender, age and occupation category of the subjects in the exit population at Tianjin port in 2019. Men, young adults and civil servants are more likely to be infected with hepatitis B. Therefore, we should focus on prevention and monitoring of the key population.
\end{abstract}

\section{Introduction}

Hepatitis B is a chronic consumptive infectious disease caused by hepatitis $B$ virus (HBV) infection. Hepatitis B patients and carriers are the main sources of infection[1]. Hepatitis B virus can be transmitted to the body through various body fluids, such as blood, semen, vaginal secretions, saliva, milk, tears, urine, etc., and can be transmitted through mother and baby, blood and blood products, damaged skin and mucosa and sexual contact[2]. Fatigue, anorexia, nausea, vomiting, anorexia, hepatomegaly and abnormal liver function were the main clinical manifestations[3]. China is the country with the most serious burden of hepatitis B disease[4]. Although the comprehensive prevention and control strategybased on prevention has been implemented and achieved certain results, China still faces many challenges in the prevention and control of hepatitis B. Not only new hepatitis B infections still occur, but also a huge number of chronic hepatitis $B$ infected people need to be managed $[5,6]$. At the same time, with the continuous development of reform and opening up and export-oriented economy, China's foreign exchanges and international cooperation are increasingly frequent, and the number of entry-exit personnel is also increasing. Tianjin Port has a large number of workers, overseas students, public servants and business personnel entering and leaving the port every year. They live and work in foreign countries, which greatly increases the risk of cross-border transmission of hepatitis $\mathrm{B}$. The purpose of this study is to provide theoretical basis for infectious disease monitoring at ports, formulate more targeted monitoring and prevention measures, strengthen the monitoring and health education of high-risk groups, and provide appropriate prevention strategies for them.

\section{Method}

\section{Sample information}

Blood samples were collected from the exit personnel of Tianjin port from January 1, 2019 to December 31, 2019, and the corresponding information database was established to record the sex, age and occupation. All samples were tested for hepatitis B antigen. The test procedure was completed by Tianjin International Travel health care center according to the strict inspection process.

\section{Inclusion and exclusion criteria}

Inclusion criteria: all subjects. Exclusion criteria: 1. The personnel who have not completed the physical examination; 2 . The first test results of the reexamination personnel; 3 . Foreigners who have settled

${ }^{\star}$ Correspondence to: Niu Guoyu, School of Public Health, WeiFang Medical University, Weifang, 261053, China, E-mail: niugy@wfmc.edu.cn

Key words: hepatitis B antigen, Tianjin port, exit personnel, electrochemiluminescence Received: August 01, 2020; Accepted: August 25, 2020; Published: August 28, 2020 
abroad in China; 4. The personnel who have undergone multiple physical examinations shall be subject to the results of the last physical examination.

\section{Antigen detection of hepatitis B}

The fasting venous blood was collected by heparin anticoagulant vacuum blood collection vessel and centrifuged at $3000 \mathrm{rmp} \times 10 \mathrm{~min}$. The hepatitis B surface antigen of exit physical examination personnel at Tianjin port in 2019 were detected using electrochemiluminescence technology, and the database of entry-exit physical examination personnel was established. The instrument and kit are from Roche diagnostic products (Shanghai) Co., Ltd. The operation steps and results were determined according to the instructions of the kit and were completed by the laboratory of Tianjin International Travel health care center according to the strict detection process.

\section{Statistical analyses}

The means, standard deviations, standard errors, and statistics analyses were calculated or performed by Prism software version 5.00. Fisher's exact test was performed to evaluate the statistical difference in the positive rate. Differences with $\mathrm{p}<0.05$ were considered to be statistically significant.

\section{Results}

\section{General information}

A total of 3469 exit physical examination personnel was tested for HBsAg in Tianjin travel health care center of 2019. Among them, 134 were HBsAg positive, and the positive rate was 3.90\% (134/3469).

\section{The gender distribution of HBsAg positive rate}

Among all the outbound physical examination personnel, the number of male was 2303, the positive rate was 5.51\% (127/2303), while the number of female was 1166 , the positive rate was $0.60 \%$ (7/ 1166). The positive rate of male was much higher than that of female, and the difference of $\mathrm{HBV}$ infection level between male and female was statistically significant $\left(\mathrm{X}^{2}=50.62, \mathrm{P}<0.001\right)$ (Table 1$)$ for details.

\section{The occupation distribution of HBsAg positive rate}

In this study, 134 people were positive for HBsAg, among which 85 were public servants, the positive rate was $69.10 \%$ ( $85 / 123) ; 30$ were positive in labor service, the positive rate was $2.06 \%$ (30/1459); 1 was positive in pilgrimage, the positive rate was $1.64 \%$ ( $1 / 61) ; 15$ were positive in crew, the positive rate was $1.02 \%$ ( $15 / 1475)$; and the number of students studying abroad was $393 \%$ (3 / 323). The positive rate of public servants was much higher than that of other occupational groups, and the difference of hepatitis B infection level among different occupational groups was statistically significant $\left(\mathrm{X}^{2}=1451.82, \mathrm{P}<\right.$ 0.001) (Table 1).

\section{The age distribution of HBsAg positive rate}

All subjects were divided into 4 groups according to their ages: 0-20 years old, 21-40 years old, 41-60 years old and over 60 years old. There were 360 and 32 people in the group of 0-20 years old and over 60 years old respectively, and no positive person was detected. Meanwhile, there were 2597 cases aged 21-40 years old, the positive rate was 3.23\% (84 / 2597 ) and 471 cases aged $41-60$ years, the positive rate was $10.62 \%$ (50 / 471). The positive rate of young adults (21-60 years old) was much higher than that of other age groups, and the difference between them was statistically significant $\left(\mathrm{X}^{2}=76.16, \mathrm{P}<0.001\right)$ (Table 1$)$.
Table 1. The comparison of HBsAg results with different characteristics

\begin{tabular}{|l|l|l|l|l|}
\hline Feature & Number & $\begin{array}{l}\text { Constituent } \\
\text { ratio }\end{array}$ & $\begin{array}{l}\text { Positive number } \\
\text { of HBsAg }\end{array}$ & $\begin{array}{l}\text { Positive rate } \\
\text { of HBsAg }\end{array}$ \\
\hline Sex & & & & \\
\hline male & 2303 & $66.39 \%$ & 127 & $5.51 \%$ \\
\hline female & 1166 & $33.61 \%$ & 7 & $0.60 \%$ \\
\hline $\mathrm{x}^{2}$ value & & & & 50.62 \\
\hline $\mathrm{p}$ value & & & & 0.001 \\
\hline Occupation & & & & \\
\hline crew members & 1475 & $42.52 \%$ & 15 & $1.02 \%$ \\
\hline public servants & 123 & $3.55 \%$ & 85 & $69.10 \%$ \\
\hline labor personnel & 1459 & $42.06 \%$ & 30 & $2.06 \%$ \\
\hline pilgrims & 61 & $1.76 \%$ & 1 & $1.64 \%$ \\
\hline overseas students & 323 & $9.31 \%$ & 3 & $0.93 \%$ \\
\hline others & 28 & $0.81 \%$ & 0 & 0 \\
\hline $\mathrm{x}^{2}$ value & & & & 1451.82 \\
\hline $\mathrm{p}$ value & & & & 0.001 \\
\hline Age & & & & 0 \\
\hline $0-20$ & 360 & $10.38 \%$ & 0 & $3.23 \%$ \\
\hline $21-40$ & 2597 & $74.86 \%$ & 84 & $10.62 \%$ \\
\hline $41-60$ & 471 & $13.58 \%$ & 50 & 0 \\
\hline$>60$ & 41 & $1.18 \%$ & 0 & 76.16 \\
\hline $\mathrm{x}^{2}$ value & & & & 0.001 \\
\hline $\mathrm{p}$ value & & $100 \%$ & 134 & \\
\hline Total & & & $3.86 \%$ \\
\hline & & & & \\
\hline
\end{tabular}

\section{Discussion}

In 2019, the overall positive rate of outbound physical examination personnel was $3.90 \%$, which was significantly lower than that of the national population (9.2\%) [7]. The possible causes were as follows: 1 . Some overseas tourists had obvious symptoms of hepatitis B, and they thought that their own physical conditions were not suitable for leaving the country [8];2. Some foreign schools strictly restricted the enrollment of hepatitis B infected persons; 3 . There are strict requirements for the physical fitness of the crew, and those with HBsAg positive are often not selected [9]; 4. There is great uncertainty in the outbound physical examination population, which may lead to sample deviation. However, the personnel structure of outbound physical examination in Tianjin travel health care center is mainly crew and labor personnel, which is quite different from the domestic population.

Among the 3469 people in this study, 2303 are male and 1166 are female. The ratio of male to female is about $3: 1$. The number of male is far more than female. More Chinese men are willing to work and study abroad. Among $134 \mathrm{HBsAg}$ positive cases, 127 were male and 7 were female. The ratio of male to female was 18.1:1. There was a significant difference between male and female $(\mathrm{P}<0.01)$. The reason may be that there are different ways and scope of social intercourse between different genders, and men's health awareness is lower than that of women. Sharing razors, drug use (sharing drug paraphernalia) and other transmission routes are more likely to appear in the male population $[10,11]$.

In terms of occupational categories, HBsAg positive people mainly concentrated in public servants, the positive rate was $69.10 \%$, which was significantly different from other occupational groups $(\mathrm{P}<0.001)$. The positive rate of public servants was much higher than that of other occupational groups, and it was far higher than that of the national population. The most likely reason is the sample deviation. Because other occupational groups have strict requirements on whether they are infected with hepatitis B $[12,13]$. For example, the vast majority of crew members and labor personnel have experienced multiple hepatitis 
$B$ tests, and some of them are receiving treatment and are no longer engaged in such occupations. As a special outbound group, pilgrims themselves have a small base number and are more likely to have sample deviation, which results in a low detection rate $(1.64 \%)$. As one of the cities with rapid economic development, Tianjin has an increasing number of overseas students. Due to their high education level, strong awareness of disease prevention and control, and some foreign schools strictly restrict the enrollment of hepatitis B infected persons, some students with positive HBsAg test results can not apply for studying abroad, thus reducing the detection rate of overseas students. Therefore, the detection rate of overseas students in the study is far lower than that of other occupational groups.

According to the age group, the proportion of young adults (21-60 years old) is relatively high, and the positive rate of hepatitis B surface antigen is also high; while there is no positive detection in the elderly over 60 years old, it may be that few people go abroad because of the inconvenience of the elderly. At the same time, there was no positive in adolescents (1-20 years old), which may be related to vaccination awareness and vaccination rate. The main purpose of young people going abroad is to study and travel. The vaccination rate of hepatitis $B$ vaccine is relatively high and the awareness of self-protection is strong [14]. With the popularization of hepatitis $B$ vaccine and the improvement of living standards, people are more and more aware of the importance of vaccination, so the vaccination rate of hepatitis $B$ vaccine in adolescents is increased, which reduces the prevalence of hepatitis B in adolescents. Teenagers are the new force of our country. It is of great significance to strengthen the awareness of prevention and control of hepatitis $B$ among teenagers and improve the vaccination rate of hepatitis $B$ vaccine.

China is a big country of hepatitis. Viral hepatitis is one of the common infectious diseases that harm the health of our citizens. Among them, hepatitis $B$ is the main infectious disease which endangers the health of our citizens because of its high infection rate, long course, complex course and difficult to cure. Hepatitis B is highly infectious and has high family aggregation. Once infected with hepatitis B, it will not only bring serious economic burden to patients and families, but also indirectly affect social and economic development [15]. Therefore, the prevention and control of hepatitis B is the top priority of disease prevention and control work. According to this study, the following countermeasures and suggestions are provided for monitoring hepatitis $\mathrm{B}$ at ports. First of all, we should put the education and publicity work of key groups in the first place of hepatitis B prevention and carry out targeted publicity work. It is very necessary to eliminate the discrimination against hepatitis B patients and create a good social atmosphere to care for hepatitis B patients. Second, we should strengthen the immune protection of outbound personnel, improve the vaccination rate of outbound personnel, and prevent the international spread of infectious diseases. Third, improve the monitoring level, strengthen the detection means, make full use of existing resources, actively carry out the quality evaluation and technical guidance of hepatitis B testing laboratory, and improve the accuracy of hepatitis B detection in the laboratory. Fourth, strengthen the protection of staff to prevent the iatrogenic transmission of hepatitis $B$.

\section{Reference}

1. Trépo C, Chan HL, Lok A (2014) Hepatitis B virus infection. Lancet 384: 2053-2063. [Crossref]

2. Wilkins T, Sams R, Carpenter M (2019) Hepatitis B: Screening, Prevention, Diagnosis, and Treatment. Am Fam Physician 99: 314-323. [Crossref]

3. Razavi-Shearer D, Gamkrelidze I, Nguyen MH, Chen DS, Van Damme P, et al. (2018) Global prevalence, treatment, and prevention of hepatitis B virus infection in 2016: a modelling study. Lancet Gastroenterol Hepatol 3: 383-403. [Crossref]

4. Fuqiang C, Hui Z (2018) Progress in the prevalence and control of hepatitis B in China Chinese Journal of viral diseases 8: 257-264. [Crossref]

5. Cui F, Shen L, Li L, Wang H, Wang F, et al. (2017) Prevention of chronic hepatitis B after 3 decades of escalating vaccination policy, China. Emerg Infect Dis 23: 765-772.

6. Mak LY, Seto WK, Fung J, Yuen MF (2019) New Biomarkers of Chronic Hepatitis B. Gut Liver 13: 589-595. [Crossref]

7. Wang H, Men P, Xiao Y, Gao P, Lv M, et al. (2019) Hepatitis B infection in the general population of China: a systematic review and meta-analysis. BMC Infect Dis 19: 811. [Crossref]

8. Heywood AE, Nothdurft H, Tessier D, Moodley M, Rombo L, et al. (2016) Pre-travel advice, attitudes and hepatitis $\mathrm{A}$ and $\mathrm{B}$ vaccination rates among travellers from seven countries. J Travel Med 24: taw069. [Crossref]

9. Lok AS, McMahon BJ, Brown RS Jr, Wong JB, Ahmed AT, et al. (2016) Antiviral therapy for chronic hepatitis B viral infection in adults: A systematic review and metaanalysis. Hepatology 63: 319-33. [Crossref]

10. Lin WS, Lee TT, Yang YH, mills ET (2019) Environmental factors affecting selfmanagement of chronic hepatitis B from the patients' perspective. J Clin Nurs 28 : 4128-4138. [Crossref]

11. Trevisan A, Giuliani A, Scapellato ML, Anticoli S, Carsetti R, et al. (2020) Sex Disparity in Response to Hepatitis B Vaccine Related to the Age of Vaccination. Int J Environ Res Public Health 17: 327. [Crossref]

12. Guo Y, Gao P, Wang H, Wu J, Bai Q, Huang L, et al. (2020) Risk factors of hepatitis $B$ virus infection between vaccinated and unvaccinated groups among spouses in 2006 and 2014: a cross-sectional study in Beijing. Hum Vaccin Immunother 16: 148157. [Crossref]

13. Tan Y, Zhang X, Zhang W, Tang L, Yang H, et al. (2019) The Influence of Metabolic Syndrome on the Risk of Hepatocellular Carcinoma in Patients with Chronic Hepatitis B Infection in Mainland China. Cancer Epidemiol Biomarkers Prev 28: 2038-2046.

14. Mouchet J, Salvo F, Raschi E, Poluzzi E, Antonazzo IC, et al. (2018) Hepatitis B vaccination and the putative risk of central demyelinating diseases - A systematic review and meta-analysis. Vaccine 36: 1548-1555. [Crossref]

15. Zeng N, Zou C, He Z, Ma H, Ou X, et al. (2018) Systematic review on the reporting quality of randomized controlled trials in patients with hepatitis B or C in China. Int $J$ Infect Dis 67: 58-64. [Crossref]

Copyright: (C2020 Cuicui S. This is an open-access article distributed under the terms of the Creative Commons Attribution License, which permits unrestricted use, distribution, and reproduction in any medium, provided the original author and source are credited. 